\title{
PENGUKURAN MODULUS ELASTISITAS DINAMIS BATUAN DENGAN METODE SEISMIK REFRAKSI
}

\author{
Ashadi Salim \\ Mathematics \& Statistics Department, School of Computer Science, Binus University \\ Jl. K.H. Syahdan No. 9, Palmerah, Jakarta Barat 11480 \\ ashadisalim@binus.ac.id
}

\begin{abstract}
The seismic wave velocity in rock formation depends on the elastic modulus and mass density of rock where the wave travels. The velocity measurement of $P$ and $S$ waves on rock formation and the mass density in the laboratory can be used for calculating the elastic modulus of rock formation. The elastic modulus is part of rock mechanical parameter needed in geological engineering researches. The velocity measurement of $P$ and $S$ waves by the seismic refraction method was done on a tunnel with 11 spreads of measurement. From the results of the measurement, three groups of rock formation could be identified. The first is rock formation with $E_{d}=8.890-12.68 \mathrm{MPa}$ and $G=3.306-4.830 \mathrm{MPa}$; the second group is rock formation with $E_{d}=8.890-12.68 \mathrm{MPa}$ and $G=3.306-4.830 \mathrm{MPa}$; and the third group is with $E_{d}=18.520-21.120 \mathrm{MPa}$ and $G=6.724-7.744 \mathrm{MP}$. The first group is clay formation while the second and third groups are andesitic stone formation.

Key Words: $P$ and $S$ wave, shear modulus, elastic modulus
\end{abstract}

\begin{abstract}
ABSTRAK
Kecepatan rambat gelombang seismik pada lapisan batuan bergantung pada sifat elastisitas (modulus elastisitas) dan rapat massa dari batuan di mana gelombang merambat. Pengukuran kecepatan rambat gelombang $P$ dan gelombang $S$ pada suatu lapisan batuan dan rapat massanya di laboratorium dapat digunakan untuk menentukan modulus elastisitas lapisan batuan. Modulus elastisitas merupakan bagian dari parameter mekanik batuan yang diperlukan dalam penelitian geologi teknik. Pengukuran kecepatan gelombang $P$ dan gelombang $S$ dengan metode seismik refraksi telah dilakukan pada suatu terowongan dengan 11 lintasan pengukuran seismik. Dari hasil pengukuran dapat diidentifikasikan tiga kelompok lapisan batuan, yaitu lapisan batuan dengan harga $E_{d}=990-2.720 \mathrm{MPa}$ dan $G=353-1.183 \mathrm{MPa}$; kelompok kedua dengan $E_{d}=8.890-12.68$ $M P a$ dan $G=3.306-4.830 M P a$; serta Kelompok ketiga dengan $E_{d}=18.520-21.120 M P a$ dan $G=6.724-7.744 M P$. Kelompok pertama merupakan lapisan batuan lempung, dan kelompok dua dan tiga merupakan lapisan batuan andesit.
\end{abstract}

Kata kunci: gelombang P dan S, modulus geser dinamis, modulus elastisitas dinamis 


\section{PENDAHULUAN}

Penyelidikan parameter mekanik lapisan batuan bawah permukaan dengan metode seismik refraksi semakin berkembang. Hasil yang diperoleh dapat memberikan kontribusi yang realistis dalam penyelesaian problem-problem geologi teknik. Dari hasil beberapa penelitian, terdapat korelasi yang baik antara kecepatan rambat gelombang longitudinal (gelombang P) dan kecepatan rambat gelombang transversal (gelombang S) dengan beberapa parameter mekanik batuan, diantaranya: modulus elastisitas, modulus geser, " voids ratio", rapat massa, porositas, "shear rigidity" (Tezan et al, 2009). Modulus elastisitas yang diperoleh dengan metode seismik refraksi ini disebut modulus elastisitas dinamis.

Keuntungan dari pemakaian metode seismik refraksi dalam pengukuran modulus elastisitas batuan secara langsung di lapangan (in situ) adalah biaya operasional yang lebih murah, waktu yang dibutuhkan relatif singkat, peralatan yang diperlukan relatif ringan sehingga mobilisasinya di lapangan relatif lebih mudah, bila dibanding dengan metode statis. Kelemahan utama dari metode ini adalah harga modulus elastisitas yang diperoleh lebih dari besar dari yang diperoleh dengan metode statik. Dalam praktek di lapangan, kedua metode ini dilakukan secara bersamaan pada suatu lokasi/daerah penelitian, dengan jumlah titik pengukuran secara statik dapat dikurangi. Hasil dari kedua metode ini dibanding untuk mengetahui korelasi antara kedua hasil pemgukuran tersebut. .

Pada penelitian geologi teknik, diantara parameter fisis batuan batuan yang selalu diteliti adalah sifat mekanik batuan, yaitu modulus elastisitas, Poisson ratio, dan shear modulus batuan. Metode penelitian yang dilakukan dapat berupa penelitian di laboratorium terhadap sampel bantuan yang diambil dari daerah penelitian, dan atau pengukuran langsung in situ, yaitu berupa sondir dan atau plate Load Test.

Pada makalah ini akan dikemukan pengukuran parameter mekanik batuan, dalam hal ini adalah modulus geser dinamis, Poisson ratio dan modulus elastisitas (modulus Young) dinamis batuan dengan metode seismik refraksi, yaitu dengan melakukan pengukuran kecepatan rambat gelombang $\mathrm{P}$ dan gelombang $\mathrm{S}$.

\section{METODE}

Setiap gangguan ("shock") yang diberikan pada permukaan atau dalam tanah, baik berupa peledakan dinamit maupun pemukulan sebuah palu akan menghasilkan gelombang yang akan merambat ke segala arah. Tiga tipe gelombang utama yang dihasilkan oleh sumber gelombang tersebut adalah: (1) gelombang kompresi (gelombang $\mathrm{P}, \mathrm{P}$ untuk pressure) dengan kecepatan rambat $\mathrm{V}_{\mathrm{P}}$, yang disebut juga sebagai gelombang longitudinal; (2) gelombang "shear" (gelombang S, S untuk shear), dengan kecepatan rambat $\mathrm{V}_{\mathrm{S}}$, yang disebut juga sebagai gelombang transversal; (3) gelombang permukaan (teruma gelombang Rayleigh). Kedalaman penetrasi gelombang permukaan ini sangat dangkal, yaitu satu panjang gelombang, hingga tidak terpakai dalam eksplorasi seismik.

Pada lapisan batuan yang sama, kecepatan rambat gelombang $\mathrm{P}\left(\mathrm{V}_{\mathrm{P}}\right)$ adalah selalu lebih besar dari kecepatan rambat gelombang $\mathrm{S}\left(\mathrm{V}_{\mathrm{S}}\right)$. Hal ini merupakan sumber kesulitan utama dalam mengidentifikasikan kedatangan gelombang $\mathrm{S}$ pada rekaman seismik, Di mana kedatangan gelombang $\mathrm{S}$ harus diidentifikasi pada bagian tengah dari rekaman seismik, di mana rekaman seismik tersebut mengandung bermacam kedatangan gelombang.

Untuk dapat mengidentifikasikan kedatangan gelombang S dengan baik diperlukan teknik pengukuran khusus, di mana sumbu geofon dipasang sejajar permukan dan tegak lurus arah lintasan 
pengukuran, demikian juga dengan sumber gelombang, yaitu berupa pemukulan palu pada suatu pelat besi atau balok kayu, dilakukan secara lateral/sejajar permukan tanah dan tegak lurus arah lintasan pengukuran (Luna dan Jadi, 2000). Sementara itu, peralatan yang digunakan pada penelitian ini, dilengkapi dengan system "signal enhancement", yang memungkinkan untuk melakukan penjumlahan gelombang (stacking). Penjumlahan gelombang dilakukan dengan merambatkan beberapa kali gelombang untuk posisi geofon dan sumber gelombang yang sama. Dengan demikian kualitas sinyal gelombang $\mathrm{S}$ dapat dimaksimalkan,

Kecepatan rambat gelombang pada suatu lapisan batuan ditentukan oleh beberapa parameter mekanik/elastik dari lapisan batuan di mana gelombang merambat, seperti rapat massa, dan modulus elastisitas batuan. Hubungan kecepatan rambat gelombang dengan parameter mekanis batuan tersebut adalah:

$$
V_{P}=\sqrt{\frac{B+\frac{3}{4} G}{\rho}}
$$

dan

$V_{S}=\sqrt{\frac{G}{\rho}}$

Dalam praktek di lapangan, data pengukuran yang diperoleh dari metode seismik refraksi adalah jarak antara masing-masing geofon dengan sumber gelombang dan waktu perambatan gelombang dari sumber ke setiap geofon, Dari data tersebut, selanjutnya dihitung kecepatan rambat gelombang $\mathrm{P}\left(\mathrm{V}_{\mathrm{P}}\right)$ dan kecepatan rambatan gelombang $\mathrm{S}\left(\mathrm{V}_{\mathrm{S}}\right)$, pada suatu lapisan batuan beserta kedalaman/tebal dari setiap lapisan batuan tersebut. Konstanta elastisitas batuan dapat ditentukan persamaan berikut (Cheng dan Johnston, 1981; Luna dan Jadi 2000; Sutopo et al, 2009 and Uyanik, 2010):

$G=\rho V_{S}^{2}$

$$
\sigma=\frac{\left(V_{P} / V_{S}\right)^{2}-2}{2\left(V_{P} / V_{S}\right)^{2}-2}
$$

$E=2 G(1+\sigma)$

di mana:

$\mathrm{G}$ adalah modulus geser, merupakan faktor proporsional antara tegangan(stress) geser dengan regangan (strain) geser; $\sigma$ adalah "Poisson ratio", merupakan perbandingan antara regangan dalam arah normal dengan regangan dalam arah transversal terhadap tegangan ; E modulus elastisitas (modulus Young), yaitu faktor proporsional antara tegangan(stress) normal dengan regangan normal. 
Dari persamaan di atas terlihat bahwa dengan melakukan pengukuran kecepatan rambat gelombang $\mathrm{P}$ dan gelombang $\mathrm{S}$ dengan metode seismik refraksi akan dapat ditentukan parameter mekanik/konstanta elastisitas suatu lapisan batuan, yang merupakan bagian dari sifat fisis batuan yang diperlukan dalam penelitian geologi teknik. Modulus elastisitas yang diperoleh dengan pengukuran kecepatan rambat gelombang $\mathrm{P}$ dan gelombang $\mathrm{S}$ ini disebut medulus elastisitas dinamis.

\section{HASIL DAN PEMBAHASAN}

Pengukuran seismik refraksi telah dilakukan pada dinding suatu terowongan. Pengukuran dilakukan untuk 11 lintasan seismik. Pada masing-masing lintasan, pengukuran dilakukan dengan 12 posisi geofon dan 3 posisi sumber gelombang, yaitu sumber pada kedua ujung lintasan( titik A dan titik B) dan sumber di titik tengah lintasan (titik C). Pada setiap lintasan, pengukuran dilakukan untuk gelombang P dan gelombang S. Dari data lapangan, waktu kedatangan gelombang pada masingmasing geofon dan jarak geofon-geofon tersebut dari sumber, selanjutnya dihitung kecepatan rambat gelombang $\mathrm{P}$ dan gelombang $\mathrm{S}$ untuk setiap posisi sumber gelombang dari masing-masing lintasan. Hasil perhitungan tersebut ditunjukan pada Tabel 1.

Pengukuran rapat massa $(\rho)$ batuan dilakukan di laboratorium terhadap sampel batuan yang diambil dari masing-masing lintasan . Harga rata-rata rapat massa tersebut untuk masing-masing jenis batuan, ditunjukan pada kolom 10 Tabel 1.

Tabel 1

Data Hasil Pengukuran Seismik

\begin{tabular}{|c|c|c|c|c|c|c|c|c|c|}
\hline \multirow[t]{2}{*}{$\begin{array}{l}\text { Lintasan } \\
\text { Pengukuran }\end{array}$} & \multicolumn{4}{|c|}{$\begin{array}{c}\mathbf{V}_{\mathbf{P}} \\
(\mathrm{m} / \mathbf{s})\end{array}$} & \multicolumn{4}{|c|}{$\begin{array}{c}\mathbf{V}_{\mathbf{S}} \\
(\mathbf{m} / \mathbf{s})\end{array}$} & \multirow[t]{2}{*}{$\begin{array}{l}\rho \rho \\
\left(\mathrm{kg} / \mathrm{m}^{3}\right.\end{array}$} \\
\hline & $\begin{array}{l}\text { Sumber } \\
\text { di titik } \\
\text { A }\end{array}$ & $\begin{array}{l}\text { Sumber } \\
\text { di titik B }\end{array}$ & $\begin{array}{l}\text { Sumber } \\
\text { di titik C }\end{array}$ & $\begin{array}{l}\text { Rata- } \\
\text { rata }\end{array}$ & $\begin{array}{l}\text { Sumber } \\
\text { di titik A }\end{array}$ & $\begin{array}{l}\text { Sumber } \\
\text { di titik B }\end{array}$ & $\begin{array}{l}\text { Sumber } \\
\text { di titik C }\end{array}$ & $\begin{array}{l}\text { Rata- } \\
\text { rata }\end{array}$ & \\
\hline 1 & 2500 & 1960 & 2300 & 2250 & 1450 & 1100 & 1380 & 1320 & 2500 \\
\hline 2 & 1420 & 1350 & 1260 & 1340 & -- & 900 & 820 & 860 & 1600 \\
\hline 3 & 2400 & 2370 & 2300 & 2360 & 1140 & 1070 & 1240 & 1150 & 2500 \\
\hline 4 & 2300 & -- & 2250 & 2280 & 1150 & -- & 1300 & 1230 & 2500 \\
\hline 5 & 2350 & 2950 & 3430 & 2910 & 1400 & 1150 & 1310 & 1290 & 2500 \\
\hline 6 & 2960 & 2580 & 2550 & 2660 & 1320 & 1360 & 1480 & 1390 & 2500 \\
\hline 7 & 1200 & 1100 & 1090 & 1130 & -- & 450 & 480 & 470 & 1600 \\
\hline 8 & 2620 & 2150 & 2780 & 2520 & 1120 & 1080 & 1300 & 1170 & 2500 \\
\hline 9 & 3060 & 2830 & 3000 & 2960 & 1250 & 1270 & 1240 & 1250 & 2500 \\
\hline 10 & 3660 & 3950 & 3450 & 3690 & 1680 & 1790 & 1440 & 1640 & 2500 \\
\hline 11 & 4250 & 3400 & 3750 & 3800 & 1980 & 1470 & 1840 & 1760 & 2500 \\
\hline
\end{tabular}

Dari data pada Tabel 1, dan dengan menggunakan persamaan 3, 4, dan 5, modulus geser dinamis $\left(G_{D}\right)$, poisson ratio dan modulus elastisitas dinamis $\left(E_{D}\right)$ dari batuan pada lokasi penelitian dapat dihitung. Hasil perhitungan tersebut ditunjukan pada Tabel 2.

Tabel 2

Hasil Perhitungan Modulus Geser , Poisson Ratio dan Modulus Elastisitas

\begin{tabular}{cccc}
\hline No. Lintasan Pengukuran & $\begin{array}{c}\text { Modulus } \\
\text { Geser }\left(\mathbf{G}_{\mathbf{D}}\right) \\
(\mathbf{M P a})\end{array}$ & $\begin{array}{c}\text { Poisson } \\
\text { Ratio } \\
(\boldsymbol{\sigma})\end{array}$ & $\begin{array}{c}\text { Modulus Elastisitas dynamis }\left(\mathbf{E}_{\mathbf{D}}\right) \\
(\mathbf{M P a})\end{array}$ \\
\hline 1 & 4.356 & 0,238 & 10.780 \\
\hline
\end{tabular}




\begin{tabular}{|c|c|c|c|}
\hline 2 & 1.183 & 0,150 & 2.720 \\
\hline 3 & 3.306 & 0,344 & 8.890 \\
\hline 4 & 3.782 & 0,295 & 9.790 \\
\hline 5 & 4.160 & 0,378 & 11.460 \\
\hline 6 & 4.830 & 0,312 & 12.680 \\
\hline 7 & 353 & 0,395 & 990 \\
\hline 8 & 3.422 & 0,363 & 9.330 \\
\hline 9 & 3.906 & 0,392 & 10.870 \\
\hline 10 & 6.724 & 0,377 & 18.520 \\
\hline 11 & 7.744 & 0,364 & 21.120 \\
\hline
\end{tabular}

Dari Tabel 2 di atas, didasarkan pada harga modulus elastisitas dinamis, batuan pada daerah penelitian dapat dikelompokan atas tiga bagian, yaitu: kelompok pertama batuan dengan modulus elastisitas dinamis $\left(E_{D}\right)=990-2.720 \mathrm{MPa}$, kelompok kedua dengan $\mathrm{E}_{\mathrm{D}}=8.890-12.68 \mathrm{MPa}$, serta kelompok ketiga lapisan batuan dengan $\mathrm{E}_{\mathrm{D}}=18.520-21.120 \mathrm{MPa}$. Demikian juga untuk harga modulus geser, lapisan batuan pada daerah penelitian dapat dikelompok atas 3 bagian, yaitu: pertama: $G_{D}$ $=353-1.183 \mathrm{MPa}$; kedua: $\mathrm{G}_{\mathrm{D}}=3.306-4.830 \mathrm{MPa}$; dan ketiga: $\mathrm{G}_{\mathrm{D}}=6.724-7.744 \mathrm{MPa}$. Pengelompokan berdasarkan modulus geser dinamis ini bersesuaian dengan pengelompakan berdasarkan modulus elastistas dinamis.

Menurut data geologi daerah penelitian, lapisan-lapisan batuan tersebut terdiri dari (Tabel 3): kelompok pertama merupakan batuan lempung, kelompok kedua merupakan lapisan batuan andesit, dan kelompok ketiga merupakan batuan andesit. Hasil tersebut menunjukan adanya dua kelompok batuan andesit, yaitu batuan andesit dengan modulus elastisitas dinamis yang lebih rendah dan satu lagi dengan modulus elastisitas yang lebih tinggi. Hal tersebut dapat disebabkan, lapisan batuan andesit dengan modulus elastisitas dinamis rendah mengalami sedikit pelapukan, sedang lapisan batuan andesit dengan modulus elastisitas dinamis lebih tinggi belum mengalami pelapukan.

Tabel 3

Data Lapisan Batuan

\begin{tabular}{llll}
\hline No. & $\begin{array}{l}\text { Modulus Geser } \\
(\mathbf{M P a})\end{array}$ & $\begin{array}{l}\text { Modulus Elastisitas } \\
\text { Dinamis (MPa) }\end{array}$ & $\begin{array}{l}\text { Jenis } \\
\text { batuan }\end{array}$ \\
\hline I & $353-1.183$ & $990-2.720$ & lempung \\
\hline II & $3.306-4.830$ & $8.890-12.680$ & andesit \\
\hline III & $6.724-7.744$ & $18.520-21.120$ & andesit \\
\hline & & & \\
\hline
\end{tabular}

Dalam penelitian geologi teknik, modulus elastisitas yang digunakan umumnya modulus elastisitas statik, yang diperoleh dari hasil pengukuran dengan metode "plate Load Test" dan atau sondir, maka pada lokasi pengukuran modulus elastisitas dinamis dengan metode seismik refraksi, juga perlu dilakukan beberapa titik pengukuran dengan metode statik. Modulus elastisitas yang diperoleh dari kedua metode pengukuran ini dibandingkan, hingga dapat diketahui korelasi antara hasil pengukuran secara dinamis dan secara statis pada daerah penelitian. Dari korelasi kedua hasil pengukuran tersebut, pada titik di mana hanya pengukuran seismik yang dilakukan, modulus elastisitas statis pada daerah tersebut akan dapat ditentukan. 


\section{PENUTUP}

Pengukuran kecepatan gelombang $\mathrm{P}$ dan gelombang S dengan metode seismik refraksi untuk menentukan modulus elastisitas dinamis batuan telah dilakukan pada dinding suatu terowongan dengan 11 lintasan pengukuran seismik. Dari hasil perhitungan modulus geser dan modulus elastisitas dinamis batuan, dapat diidentifikasi tiga kelompok lapisan batuan, yaitu lapisan batuan dengan harga $\mathrm{E}_{\mathrm{d}}=990-2.720 \mathrm{MPa}$ dan $\mathrm{G}=353-1.183 \mathrm{MPa}$ yang merupakan lapisan batuan lempung. Kelompok kedua dengan $\mathrm{E}_{\mathrm{d}}=8.890-12.68 \mathrm{MPa}$ dan $\mathrm{G}=3.306-4.830 \mathrm{MPa}$ yang merupakan lapisan batuan andesit yang sedikit mengalami pelapukan. Kelompok ketiga dengan $\mathrm{E}_{\mathrm{d}}=18.520-21.120 \mathrm{MPa}$ dan $\mathrm{G}=6.724-$ 7.744 MPa yang merupakan lapisan batuan andesit yang belum mengalami pelapukan.

\section{DAFTAR PUSTAKA}

Cheng, C. H. and Johnston, D. H. (1981). Dynamic and static moduli. Geophysical Research Lettres, $8(1), 39-42$.

Luna, R., and Jadi, H. (2000). Determination of dynamic soil properties using geophysical methods. Proceeding of the First International Conference on The Application of Geophysical and NDT Methodologies to Transportation Facilities and Infrastructure, St. Luis, Desember, 2000.

Sutopo; Ibrahim, E.; Kurniati, N. Lasmana, F. (2009) . Studi modulus elastisitas (modulus young) untuk karakterisasi berbagai jenis batubara berdasarkan analisis kecepatan gelombang. Jurnal Penelitian Sains, 12 (2B), 12203-1 -12203-5.

Tezcan, S. S., Ozdemir, Z. dan Keceli, Z. (2007). Seismic technique to determine the allowable bearing pressure for shallow fondations in soils and rock. Acta Geophysica, 57 (2).

Uyanik, O. (2000). Compressional and shear-wave velocity measurements in unconsolidated top-soil and comparison of the results. The International Journal of The Physical Sciences, 5 (7), 1034-139. 